\title{
Personality and Emotion-Based High-Level Control of Affective Story Characters
}

\author{
Wen-Poh Su, Student Member, IEEE, Binh Pham, Member, IEEE, and \\ Aster Wardhani, Member, IEEE
}

\begin{abstract}
Human emotional behavior, personality, and body language are the essential elements in the recognition of a believable synthetic story character. This paper presents an approach using story scripts and action descriptions in a form similar to the content description of storyboards to predict specific personality and emotional states. By adopting the Abridged Big Five Circumplex (AB5C) Model of personality from the study of psychology as a basis for a computational model, we construct a hierarchical fuzzy rule-based system to facilitate the personality and emotion control of the body language of a dynamic story character. The story character can consistently perform specific postures and gestures based on his/her personality type. Story designers can devise a story context in the form of our story interface which predictably motivates personality and emotion values to drive the appropriate movements of the story characters. Our system takes advantage of relevant knowledge described by psychologists and researchers of storytelling, nonverbal communication, and human movement. Our ultimate goal is to facilitate the high-level control of a synthetic character.
\end{abstract}

Index Terms-Computing methodologies, simulation, modelling, visualization, types of simulation, animation, computer applications, social and behavioral sciences, psychology.

\section{INTRODUCTION}

C URRENT narrative intelligence research emerges from several areas such as interactive drama, interactive cinema, virtual theater, immersive storytelling, and emergent storytelling. Generally, such research can be divided into three major groups [1]: authoring, story, and characterbased models. They aim to address the problem of generating interactive narratives and different narrative design approaches for user experience. To a character-centric storytelling system, character expression is the essence of believability. This paper focuses on three essential tasks for devising a better character controlling mechanism as follows: 1) modeling high-level psychological directives, 2) classifying body languages used in story performance, and 3) devising story input module to decode the meaning of narrative contexts .

First, personality, emotion, self-motivation, social relationships, and behavioral capabilities are the fundamentals for providing high-level directives for autonomous character architecture. The conceptual diagram of our system is shown in Fig. 1. Personality and emotion trigger the expressiveness and behaviors of a character. Personality can be used to predict the type of a story character and her/ his behavior type. Emotion and behavior types influence the representation of an individual including the stance, walking posture, gesture, facial expressions, etc. There are some previous computational models related to personality. Chittaro and Serra [2] proposed a goal-oriented approach to character programming based on probabilistic automata

- The authors are with the Faculty of Information Technology, Queensland University of Technology, GPO Box 2434, Brisbane, QLD 4001, Australia. E-mail:w.su@student.qut.edu.au, \{b.pham,a.wardhani\}@qut.edu.au.

Manuscript received 22 Aug. 2005; revised 25 Dec. 2005; accepted 16 Mar. 2006; published online 10 Jan. 2007.

For information on obtaining reprints of this article, please send e-mail to: tvcg@computer.org, and reference IEEECS Log Number TVCG-0114-0805. and personality. Rousseau [3] has developed a model of personality based on Myers-Briggs psychology theory and used in a virtual theatre project. Our model of personality traits is based on De Raad's Abridged Big Five Circumplex (AB5C) Model [4], which systematically classifies personality traits to detail analysis. Likewise, emotional synthesis is a perennial challenge. Amaya et al.'s "emotion transform" [5], Unuma et al.'s Fourier function models [6], Rose et al.'s Motor Interpolation System [7], and Wilson's artificial emotion engine [8] are designed to generate varieties of rich emotional behaviors for autonomous characters. Moreover, Velasquez investigated a model of emotions, mood, and temperament that provides a flexible way of controlling the behavior of autonomous entities [9]. Perlin and Goldberg used stochastic noise functions to simulate personalities and emotions in exiting animation [10], [11]. Similarly, our character motion derives from the understanding of emotional behavior and elements of human personality. We alter character motions derived from procedure animations. Comparatively, our approach focuses on integrating both compositive factors of personality traits and emotions with character motions. These cognitive factors are analyzed to map to the behavioral characterization of characters. Our motion model is controlled by a fuzzy logic controller of psychological elements, resulting in different subtle performances.

Second, interpersonal communication is characterized not only by verbal, but also by visual communication. Between 60-80 percent of our message is communicated through our body language and only 7-10 percent is attributable to the actual words of a conversation [12]. Nonverbal communication includes facial expression, gaze, gesture, posture, bodily contact, spatial behavior, nonverbal vocalizations, clothes, and the other aspects of appearance [13]. Several researchers have built animated embodied conversational agents that synthesized speech with animated hand gestures. Chi et al.'s "Emote" system is based 


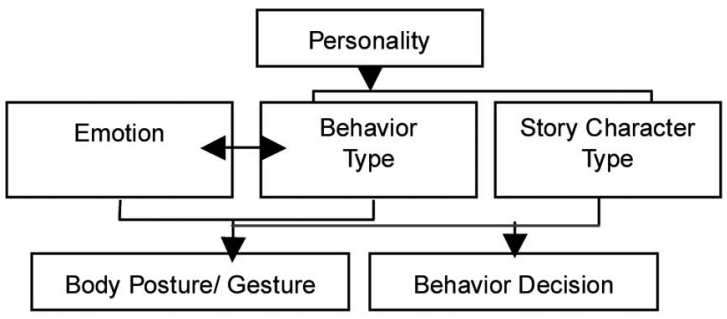

Fig. 1. Hierarchical structure of personality and emotion effects.

on Laban Movement Analysis (LMA) for an expressive motion and upper-torso gesture synthesis [14]. Egges et al.'s motion synthesizer is for posture variation and personalized change of balance using motion captured example animations [15]. In their BEAT project, Cassell et al. used the McNeill gesture and dialogue semantics to generate the gesturing behavior of autonomous characters [16]. Andre et al. generated pointing gestures as a subaction of the rhetorical action of labeling [17]. Stone et al. spliced together clips of sound and motion and resynchronized them to create an animated delivery of a meaningful utterance [18]. Most of the previous works focus on gestures performed by hands and arms. However, there are other signals used during communications, for instance, body posture. Moreover, in a story performance, a set of predefined motions is usually used repetitively. Therefore, we focus on finetuning these exiting motions by modulating the variations in personality to differentiate the actions of different characters.

Third, we study the character acting and reacting believability in story dialogues from the perspective of nonverbal communication to characters' postures and actions. Researchers transcribed the scripts and actions from a moment of a film [19] to support natural language generation and action. However, in a computational narrative interaction, synthetic actors who display their body languages directly derived from an action selection mechanism usually lack the refined modification of personality and emotion. Moreover, nonverbal communication and psychological ingredients are not taken into account. We study believable agents that use nonverbal communication derived from psychological models (personality and emotional state) to influence their behaviors. We focus on how to analyze the character personality and emotion from specific context information in a form similar to the content description of storyboards.

The overall goal of our system is to provide a visual platform for these intelligent actors to simulate storytelling sequences with consistent personality performance and reflection of inner feelings or emotions. A schematic diagram of system overview is shown in Fig. 2. From story contexts, the meaning of the text itself and the character's body languages are annotated to predict the possible personality type and emotional status of a character. The results are then used as inputs to the Personality and Emotion (P\&E) Engine. In the P\&E engine, the personality type coupling with emotional inclination results in the character's possible postural values. The character has a set of possible gestures and postures assigned to maintain the consistency of the character performance.

In Section 2, we analyze research questions and challenges. In Section 3, we examine the relationships

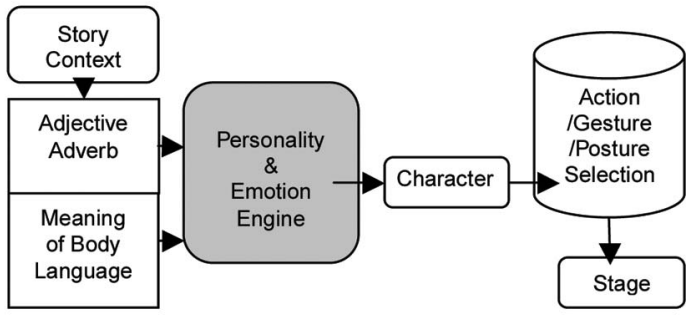

Fig. 2. System overview.

between narrative intelligence and the essentials of dynamic character design. Our computational model and the analysis of some testing results are covered in Section 4. Finally, we conclude by discussing evaluation and the scalability issues for this approach.

\section{Modeling Believable Story Characters}

In order to provide a visual platform for these intelligent actors to simulate storytelling sequences, a good dynamic character design for the storytelling environment is essential.

We examine the following scripts: Mary's face was pale with fear. She shrank down, looked back at the dark street, and said "Someone help me." In a story, actions and body languages are generally described together to accomplish communication goals. Can we analyze story scripts to present these fundamental factors and provide sufficient information for characters' performance? For instance, a girl might be upset with the stranger approaching in accord with her personality and with her emotion upon being lost. She may cross her arms as a nonverbal expression to manifest defensiveness, rejection, and irritation. These types of nonvocal expressions cannot be decoded in speech or dialogue recognition processes. Therefore, we develop the following research questions:

- How can we derive and differentiate the varieties of dialogues, descriptions, and action data from context information?

- How can we provide sufficient action descriptions of a story character in text for reasoning?

- How can a system decode the context to provide an approximate choice for a story character movement?

- How can we create a context database ("semantic" action plan) for the interpretation of body language?

The acting believability of a synthetic character indicates a character having styling behaviors which derive from the psychological factors. In order to model an autonomous story character that can perform believable acting behavior, we have to consider the question "What makes a great character?" A great story character must have self-contradictory personalities [1]. They have one or more extraordinary admirable traits or exaggerated emotional reactions than other personae. Therefore, we consider the following questions:

- What are the characteristics of empathic story roles?

- Is it possible to find relevant parameters to express personality and emotion? Can they be categorized? 
A good story character must be attractive. In Disney animation, animated characters are generally appealing. Basically, these characters are simply more interesting due to their exaggerated traits which urge the strength of emotion. Therefore, we deliberate the following research questions:

- How do personality and emotion affect human motion categorization?

- What are the main parameters of the motion which represent a story character's motion?

Personality and emotion may vary along the unfolding story plots. The transition of a persona must be considered while we design a synthetic character model.

- How can a story character engine provide unpredictable possibilities?

- How can a scalable model of a story character's motion be constructed?

Moreover, body languages vary with diverse personality types and emotional states. Every person has a distinctive characteristic of standing, walking, sitting, and gesturing based on the personality types and emotional states. A neurotic person may have some unconscious behavior such as nibbling a finger, wringing the hand, and scratching the face. An easygoing person may slump his/her shoulders and have more eye contact with others. Personality influences the patterns of our body language and gives us distinctiveness.

- What do body languages derive from the personality types? How do emotions relate to body movements?

In the rest of this paper, we analyze our progress towards responding to these challenges.

\section{Requirements for Story Characters}

With the aim of examining the basic elements of a good story character design, we study the basic roles of story characters, the driver of human behaviors, and the relationship of human personality, emotion, and behavior, especially nonverbal behavior. Based on these descriptions, we are able to analyze the personality, emotion, and behavior inclination of a story character as well as to provide rules to our fuzzy system.

\subsection{Story Character Roles}

The structures of characters depend on their roles in the story. Following Propp [20], we consider the model of five basic roles: protagonist, helper, neutral, hinder, and antagonist. This model is now described in some detail.

A protagonist must be empathetic and act out of positive passions such as love, justice, and truth. Mostly, a protagonist has a conscious desire but may also have a self-contradictory unconscious desire. A helper may be a guardian of integrity giving the protagonist some guidance of success. A neutral can be a subordinate actor or a cheerful crowd of people. A hinder often jeopardizes the hero's chance of success by giving bad or ignorant advice and acts in an immature, cowardly manner. Finally, an antagonist (villain) acts out of negative passions, such as greed, fear, abhorrent, or revenge, whose dark side is stronger [21], [22]. In general, really interesting characters do not consist of such obvious distinctions but are driven by more complex complications. Personality and emotion are the main ingredients making synthetic autonomous characters interesting to people.

\subsection{The Driver of Story Characters' Behaviors}

A synthetic story character should choose actions that are consistent with her/his personality. Personality is the component of psychology traits that distinctively characterize an entity. The emotion of a story character results from the story events and the persona reacts on her/his action. Emotion also plays a significant role in the human decisionmaking processes and has a major impact on human memory, thinking, and judgment in behavior decisions. In addition, personality affects the intensity of emotion. Emotional intensity refers to the total emotional impact of a given event [23]. For example, people who have optimistic traits are inclined to have positive emotions longer than pessimistic people. Emotional intensity urges one to behave in particular ways.

\subsubsection{Personality}

Personality distinctively characterizes an entity and is represented by basic, coherent, consistent, and unique responses not only externally, but also internally. The internal response is the motivational state of thinking, feeling, mood and emotion state. The external response results in acting, disposition, stance, gesture, posture, and social behavior of people. For example, if a person has an open-minded and extroverted personality, he/she will be happy if someone offers him/her some help. He/she usually stands at ease in an open posture and smiles. Normal human beings show not only a pattern of verbal, but also nonverbal cues which are considered as part of the personality.

The mental state and cognitive characteristics of a person can be explained by the combinations of personalities. The Five-Factor Model (FFM) or "Big-Five" model of personality inventory is known as openness, conscientiousness, extroversions, agreeableness, and neuroticism (OCEAN) [24]. They were often used as the parameters of personality by many researchers (e.g., Chittaro and Serra [2], Kshirsagar and Magnenat-Thalmann [25], Egg et al.'s [26], etc.). The basic characteristics formulate what each trait means in the following:

Openness: creative, imaginative, independent, and divergent thinking.

Conscientiousness: responsible, orderly, and dependable.

Extroversion: talkative, social, and assertive.

Agreeableness: good-natured, considerate, cooperative, and trusting.

Neuroticism: anxious, temperamental, and prone to depression or worriment.

With the intention of analyzing the types of story characters, we assume that each description alone for each of these five factors is insufficient to mediate or categorize anthropopathic behaviors. Therefore, we study the analysis 
in the AB5C model [4]. Unlike OCEAN, which is used individually to distinguish people, this model refers to the combinations of two traits that are the most characteristic of an individual. The most prominent traits (positive or negative) are used to describe the distinctive traits. It provides descriptive personality terms of 90 resulting combinations. For example, a person who is positive or high in agreeableness and extroversion (in the form of A+, $\mathrm{E}+$ ) is described as merry, cheerful, sociable, enthusiastic, and happy.

In addition, we study the psychological research of reflections on personal diversity [27] and risk inclination [28] which shows how the combinations of personality factors might differ in terms of learning style, motivation, personality disorders, and risk proneness. Based on these theories, we can provide some measure of predictability by simplifying 90 combinations to 32 resulting combinations of personality traits in order to analyze the inclination of roles and behavior modes of a persona. For instance, one may have positive/high in openness, neuroticism, and negative/ low in agreeableness, extraversion, and conscientiousness traits, in our form of HLLLH (or +- - - + to note OCEAN, respectively). The description of this type shows this person is unconventional, skeptical, rude, ill-temperated, aggressive, juvenile delinquency, etc. This person is prone to be an antagonist and very cold in his/her behavior. Following this method, 32 personality combinations provide sufficient descriptive lexicons for a computational personality model.

\subsubsection{Emotion}

People usually use their facial expressions, gestures, verbal pitches, and postures to express their emotional state [29]. Some body languages reflect prevailing emotional states, such as anxiety and aggression. Emotions can be divided into two layers: momentary emotion and mood. Momentary emotions are the behaviors that we display briefly in reaction to events (e.g., angry, happy, or sad). Moods are prolonged emotional states caused by the cumulative effect of momentary emotions (e.g., blissful or scolded) or physical statuses (e.g., weary or energetic). Moods and emotions are only differentiated in terms of levels of arousal. We follow Ekman's six emotional expressions [30]: happiness, sadness, anger, surprise, fear, and disgust/ contempt, because they are not only clear, but also sufficient for computational emotion modeling. We use the strength of emotion intensity from neutral, low, to high as thresholds.

Emotions and moods are displayed in our bodily movement more apparently than personality. The attitude toward other people displays the interpersonal relationship. Liking (warm behavior) indicates positive emotional intensity last longer, e.g., a shift of posture toward another person, a smile, direct eye contact. Liking is distinguished from disliking by a more forward lean, a closer proximity, drawing back of legs, more eye gaze, more openness of arms and body, more direct body orientation, more touching, more postural relaxation, and more positive facial and vocal expressions. Disliking (cold behavior) manifests negative emotional intensity last longer as the low threshold for anger. A cold person looks around the room with slumped, drummed fingers, and hands on hips without smile. A bored person supports his head on hands, drops
TABLE 1

Nonverbal Indicators: Liking versus Disliking [32]

\begin{tabular}{|l|l|}
\hline Liking(warm behavior) & Disliking(cold behavior) \\
\hline Forward-leaning during encounters & Bodily rigidity \\
\hline Facing the other individual & Indirect bodily orientation \\
\hline Open body posture & Close-bodily posture \\
\hline Affirmative head nodding & Turn away \\
\hline Moderate amounts of gesture & A relative absence of gestures \\
\hline Close interpersonal distance & Keep distance \\
\hline Moderate body relaxing & Bodily tension \\
\hline More touching & Arms-akimbo \\
\hline Maintaining eye contact & Visual inattentiveness \\
\hline Smiling & Unpleasant facial expression \\
\hline Assuming similar postures & Incongruent postures \\
\hline
\end{tabular}

his head, turns his head away, lowers his trunk, leans backward, changes his head/arm posture, or stretches out his legs [31]. Table 1 shows the parallelism. We utilize these two types as the guiding principle for ruling emotion intensity shown in human motion. For instance, the movement of a cold person, even though he/she is highly happy, still displays less postural relaxed, less touching than a warm person does.

\subsection{Nonverbal Behavior: Posture and Gesture}

Behaviors are the indicators with which a spectator gauges a character's mood or mental state. Behaviors are more conceptual notions that include intention, reasoning, desire, verbal, and nonverbal expression. Movements along with facial, gaze, touching, gesture, and posture expressions comprise the representation of behavior, which are also called body language. Normal human beings manifest a pattern of nonverbal cues which are considered as part of personality. There is no such thing as a fixed posture in real life. Every person has a distinctive way of standing, sitting, lying, and moving. These bodily signals convey the interlocutor's true feelings and how well the words are being conveyed and received. Postures and gestures make up bodily movement. Movement is the action-sequence with varying components. Lamb and Watson defines a gesture as an action confined to a part or parts of the body, while posture is an action involving a continuous adjustment of every part of the body with consistency in the process of variation [33].

In comparison with facial and upper torso gesture expressions, postures draw less attention from computer scientists. Posture is a key indicator of the intensity of some emotion states and also plays a major part of nonverbal communications. Postures are more limited in number than gestures. However, postures are most effectively used to communicate such interpersonal attitude (e.g., friendly and hostile). According to Argyle's psychology book [13], posture is an indicator of the degree of involvement, the degree of status relative to other participants, or the degree of liking for other interlocutors. Posture defines a period of interaction longer than a gesture and shorter than a spatial position. Together with facial expressions, postures are the best way to communicate emotions and state-of-mind. For 
TABLE 2

Examples of Postures

\begin{tabular}{|l|l|l|}
\hline $\begin{array}{l}\text { Body } \\
\text { parts }\end{array}$ & $\begin{array}{l}\text { Non-Verbal } \\
\text { Behavior }\end{array}$ & Meaning of Body Language \\
\hline Head & Turning away & Hate, revulsion, contempt, bored \\
\cline { 2 - 3 } & Chin down & Humiliation, shame, shy, refuse, bored \\
\hline \multirow{2}{*}{$\begin{array}{l}\text { Upper- } \\
\text { torso }\end{array}$} & Drooping back & Listless, relax, enjoyment, frustration \\
\cline { 2 - 3 } & Erect back & $\begin{array}{l}\text { Honest, gratification, nervous, angry, } \\
\text { fear, scared }\end{array}$ \\
\hline \multirow{2}{*}{ Legs } & Draw back & Refuse, fear, polite, interested, alert \\
\cline { 2 - 3 } & Stretching out & Bored, relax, enjoyment, lax \\
\hline
\end{tabular}

instance, a forward leaning posture can indicate higher interest or more liking and a backward leaning posture is related to disgust or contempt. Besides, a tense and rigid posture is associated with anger. These nonverbal communications which add extra channels of communication over language can be broken down further and described in terms of specific body parts. Body postures comprise the overall movement of head, neck, spinal, arm, shoulder, and hip movements. The meanings of postures in Table 2 are examples.

There are a great deal of gestures during social interaction. Gestures comprise the body parts of arms, hands, fingers, legs, and feet movement. Gestures which are used for interpersonal messages include three main kinds of gestures: 1) emblems, 2) illustrators, and 3) self-touching. Emblems are usually hand-movements which have a direct verbal translation (e.g., the hitchhike sign and the V sign). Illustrators are movements related to speech to illustrate what is being said verbally (e.g., "up" and "down," "you" and "me"). Self-touching is an emotional expression (e.g., interlocking of hands, hiding the face, and feeling cold). The meanings of gestures in Table 3 are examples.

An individual is consistent in his/her style of gestures and postures. For instance, an extrovert usually has more expansive bodily movement, and it has been found that mental patients use fewer hand movements, but touch themselves more than others do. A person's gestural style is partly a product of his cultural and occupational background, power and status, age, sex, health, as well as fatigue. However, we exclude these complex factors and

TABLE 3

Examples of Gestures

\begin{tabular}{|l|l|l|}
\hline Body & $\begin{array}{l}\text { Non-Verbal } \\
\text { Behavior }\end{array}$ & Meaning of Body Language \\
\hline \multirow{2}{*}{ Head } & node & Confirmative, respectful, polite \\
\cline { 2 - 3 } & shake & Objective, denying, sorry \\
\hline Shoulder & Shrug & Confuse, aimless \\
\hline Arms & Folding arms & $\begin{array}{l}\text { Angry, refuse, thinking, defensive- } \\
\text { ness }\end{array}$ \\
\cline { 2 - 3 } & $\begin{array}{l}\text { Clenched in } \\
\text { lower position }\end{array}$ & $\begin{array}{l}\text { Depressed, tired, refuse, remorse, } \\
\text { pity, disagree, nervous, guilty }\end{array}$ \\
\hline \multirow{3}{*}{ Hands } & Tapping fingers & Boredom, nervousness, anxious \\
\cline { 2 - 4 } & $\begin{array}{l}\text { Scratching } \\
\text { head }\end{array}$ & Disagree, puzzled, shy, anxious \\
\cline { 2 - 3 } & Cover face & Humiliation, anxious, sad, fear \\
\hline
\end{tabular}

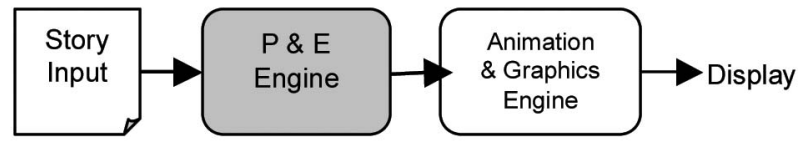

Fig. 3. The overview of system architecture.

deploy commonly used gestures to simplify the system for computational purposes.

\section{Computational Model}

The whole appeal to a player's participation in the character-centric narrative interaction is that the player can make some differences to what happens by exerting control. Narrative has traditionally frustrated the audience's desire for control [1]. Our approach is to give storytelling players/designers the chance to control autonomous characters through high-level personality and emotion-controlling mechanisms. Therefore, we adopt the patterns of personality and emotion defined by psychologists as computational linguistic variables.

\subsection{Software Architecture}

With the intention of designing a better controlling mechanism, our system consists of four parts (Fig 3): story input, Personality and Emotion (P\&E) engine, Animation and Graphics engine, and display for visualization purposes. A story designer or player can either set up the combinations of personality and emotion parameters or utilize a descriptive storyline as inputs to the P\&E engine. The P\&E engine provides consistent measurement of predictability for story character types, behaviors, and appropriate posture motions. It is a controller for providing the visual presentation to the Animation and Graphics engine. The Animation and Graphics engine receives the outputs from the P\&E engine and generates key postures and a mixed movement of the posture animation by using a linear interpolation algorithm. It is also responsible for maintaining the geometric model and for controlling the rendering process as well as displays.

\subsection{Story Input Module}

Generally, in story or transcribed scripts, writers describe richness in feelings and eloquence in expressions which give the ideas of whether someone is quick, lazy, anxious, gentle, keen, enthusiastic, and so on. Likewise, we can access one's behaviors from a film and from a photo in which we can judge how they look, and describe someone as attractive, dignified, slight, fat, tall, pompous, handsome, or imposing. However, in story scripts without the perceptual hand sketching of graphics, how can a computational synthetic character interpret in order to perform expressively? Sophisticated artists recognize these principles and properly apply them in drawing, animating, acting, or writing. Can we decode the scripts to provide sufficient information for characters' performance?

Therefore, we devise a story structure which adopts the ideas of storyboard from film production. A storyboard is formed by multimedia combining images, text, and audio explanation to give a basic overview of the content and 


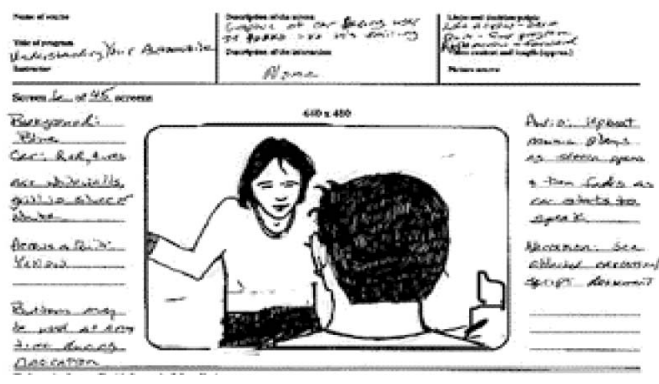

Fig. 4. Storyboard example.

functionality of the scenario. Storyboarding plays an important role in TV, film, documentary, and animation production (Fig. 4). It is a communicative tool for a production crew. In a performance, a script supervisor takes detailed notes recorded in the script of all production information: scene, take number, camera position, performance continuity, dialogue changes, and running time of each shot. A director is responsible for translating the screenplay into images and sounds. She/he directs the cast and crew from pre through postproduction.

Using a similar method, we translate the screenplay of characters' manners in detail texts to replace hand sketches. For instance, the girl stares at the stranger and stands at a distance. She nibbles her fingernails with one suitcase grabbed tightly in her other hand. This can be decoded as the girl is skeptical, anxious, impolite, careful, introverted, and nervous about facing the stranger. By annotating the descriptive meanings of body languages and story scripts, we are able to collect the relevant adjectives and adverbs. By accumulating all the descriptive lexicons, we are able to evaluate the maximum frequency of keywords and the time of emotional transitions. We devise a gestural and postural lexicons look-up table. The cumulative meanings of body languages can be used to predict the possibility of personality type and emotional state. From the previous example, the personality of the girl can be concluded to be low in openness, high in conscientiousness, low in extroversion and agreeableness, and high in neuroticism based on our system. Her reasoning and learning, leadership styles, and emotional stability in terms of descriptive lexicons can be found in one of our 32 personality types. The result of the example represents in the form of LHLLH (OCEAN respectively) in our 32 personality combinations. The parts of the description are shown as follows:

(O-L, C-H) Conventional, traditional, prim, mundane, lawabiding.

(E-L, A-L) Unsociable, uncommunicative, exclusive, rough, abrupt, crude, introverted.

(E-L, N-H) Lonely, weak, cowardly.

(A-L, N-H) Demanding, selfish, ill-tempered, irritable, temperamental, defensive.

Moreover, the emotional transition is also an output from story scripts and action descriptions. We devise the emotion based on the numerated scenes. Time factor is considered as well along with the mood changing to provide a reference for the Animation and Graphics engine. A comprehensive example is discussed in Section 4.5.2.

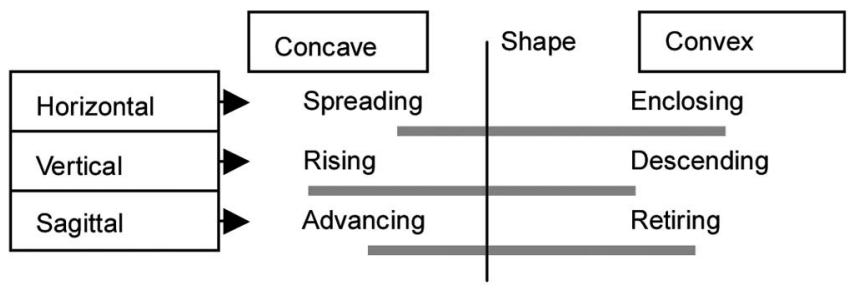

Fig. 5. Three main zones of shaping [33].

\subsection{Mapping Personality and Emotion to Body Movement}

Lasseter [34] suggested that in order to make a character's personality real to an audience, the character must be different from other characters on the screen. A simple way to distinguish the personalities of the characters is through the contrast of movements. According to our hypothesis, the combinations of personalities and emotions are able to motivate the motion. The question is what are the main parameters of the motion which characterize the body language and posture of a real human? According to Lamb and Watson's schema, a person shows some posture inclination toward one kinematics zone [33] as a habitual posture or a postural profile. The kinesphere of the human body is divided into three shaping zones: horizontally, vertically, and sagittally oriented (Fig. 5). The kinesphere represents the metaphor of planets moving into orbit around the sun. People can cause an orbiting vapor trail around their own body center through the way they shape out the movement. The first three on the left produce a closed and concave shape and the second three on the right have an open and convex shape. A person shows some inclination toward one zone.

Moreover, following Bull [31], we divide body movements into four main areas: head, trunk, upper limbs, and lower limbs, which are used to facilitate the analysis in the body movement scoring system for psychology study. In Table 4, we summarize the relationship of personality, emotions, kinesphere posture principles, and four main body areas. Positive emotions resemble happiness and surprise. Negative emotions indicate sadness, fear, anger, and disgust. These emotions effect one's movement inclination of kinesphere zones. Likewise, the personalities correspond to likely body movements. For instance, a person having $\mathrm{E}-\mathrm{H}, \mathrm{A}-\mathrm{H}$, or $\mathrm{N}-\mathrm{L}$ in his/her personality combination is more merry, cheerful, sociable, enthusiastic, and happy. This person demonstrates the inclination as more spreading in the horizontal, rising in the vertical, and retiring in the saggital zone as his/her habitual movements.

\subsection{Fuzzy Logic Controller for P\&E Engine}

Using the parameters of personality, emotion, and behavior described in Section 3, the hierarchical Multiple Input Multiple Output (MIMO) Fuzzy Controllers (FLCs) of the P\&E engine are implemented. The architecture of the P\&E engine comprises a personality FLC module and an emotion FLC module. The first layer of our system provides a predication of the category of story characters as well as the inclination of behavior modes. These results can provide guidelines for emotion intensity and body language selections for the consistent distinction of story characters. 
TABLE 4

Emotions and Four Main Areas of Body Movement

\begin{tabular}{|c|c|c|c|}
\hline Emotion & $\begin{array}{l}\text { Positive } \\
\text { Emotions }\end{array}$ & $\begin{array}{l}\text { Negative } \\
\text { Emotions }\end{array}$ & Kinesphere \\
\hline Personality & E-H, A-H, N-L & E-L,A-L,N-H & Zone \\
\hline Head & Face up & Chin down & Vertical \\
\hline \multirow[t]{2}{*}{$\begin{array}{l}\text { Upper } \\
\text { Limbs }\end{array}$} & $\begin{array}{l}\text { Elbows open or } \\
\text { Armpits exposed }\end{array}$ & Arms crossed & Horizontal \\
\hline & $\begin{array}{l}\text { Hands placed } \\
\text { behind the head }\end{array}$ & $\begin{array}{l}\text { Hands clenched } \\
\text { in lower position }\end{array}$ & Vertical \\
\hline \multirow[t]{2}{*}{ Trunk } & Leans backward & Leans forward & Sagittal \\
\hline & Back straight & Back lowered & Vertical \\
\hline $\begin{array}{l}\text { Lower } \\
\text { Limbs }\end{array}$ & Jump or trot & Draggy or saggy & Vertical \\
\hline
\end{tabular}

Subsequently, in the second layer, emotions are coupled with the types of story character and behavior in order to construct reasoning rules of the body posture and body language selection (Fig. 6). Therefore, an idle character performs the habitual movement and body languages according to his/her personality. While one momentary emotion strikes, the character performs his/her role based on the intensity of this emotion.

Uncertainty is an important aspect of human behavior. Fuzzy systems are usually used to model domains containing uncertainty and generally built to replace a human expert with a machine using the logic a human would [35]. Fuzzy logic has been used to model autonomous characters. For example, El-Nasr et al. [36] used fuzzy logic to represent emotion for mapping events and observations to emotional states through a simulation of a pet and the facial expression of a baby agent. Bui et al. [37] generated facial expressions from emotions using a fuzzy rule-based system. Fuzzy logic provides an expressive language for linguistic descriptions of the model and enables our model to produce some complex emotional states and behaviors. We map the patterns of personality and emotion based on psychological theories to computational linguistic variables by a fuzzy system.

\subsubsection{Personality FLC Module}

The personality FLC module is devised for reasoning the type of story characters and behaviors. A fuzzy logic system

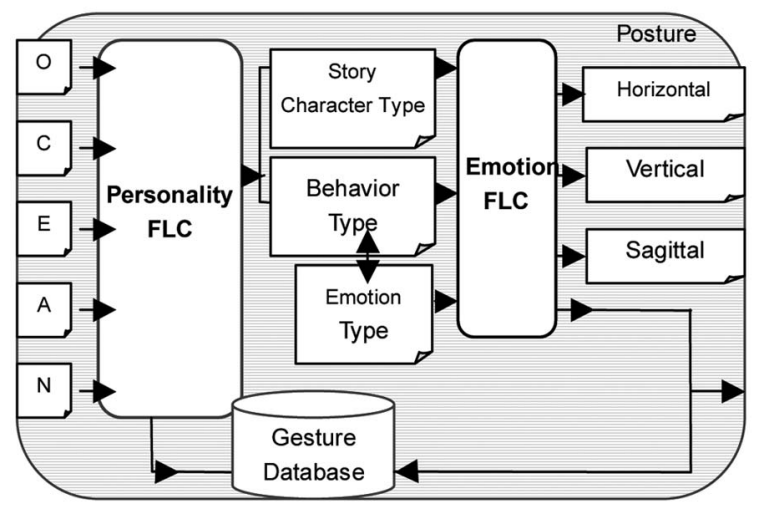

Fig. 6. Hierarchical fuzzy controller of the P\&E engine.

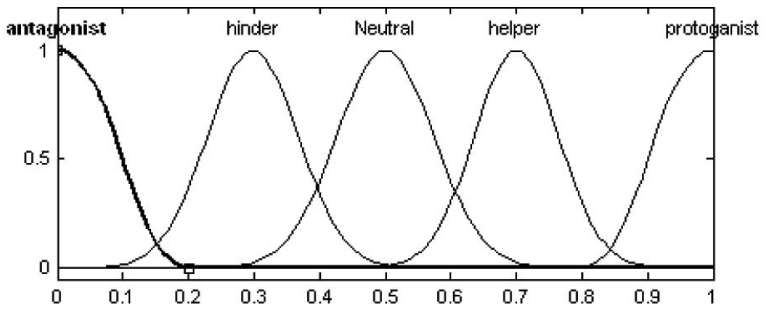

Fig. 7. Membership functions for the output character type.

is comprised of four main components: the fuzzification, the fuzzy rule base, the fuzzy inference engine, and the defuzzification [35]. Fuzzification taks the information provided by real input data and converts it to be recognizable by the fuzzy system. It enables grouping imprecise data that have similar meaning, but distinctive concrete representations. The form of fuzzification can be done by using a fuzzifier function that determines the degree of fuzziness in a set. A fuzzy set that defines the implication relation can be expressed in a number of ways, e.g., a triangular, trapezoidal, or bellshaped membership function. An example of membership function is in Fig. 7. The degree to which an object belongs to a fuzzy set is called the membership value in the set. It uses the whole continuous interval between 0 (False) and 1 (True) to describe human reasoning. Next, fuzzified data are applied to the fuzzy rule base section. In the fuzzy inference engine, the result of the rule base section is the fuzzified output data. The fuzzified output data are converted back to real data by a defuzzification process.

Based on the description of five basic story roles and the adjectives for positive (high) and negative (low) traits of the AB5C model used to describe the personalities, we analyze the combinations of personality for the types of characters and behaviors. Each of the OCEAN traits is at the threshold of low and high as described in the AB5C Model, for instance, high in openness and low in other traits can be described as $\mathrm{O}-\mathrm{H}, \mathrm{C}-\mathrm{L}, \mathrm{E}-\mathrm{L}, \mathrm{A}-\mathrm{L}$, and N-L as one personality type. We describe each of the five personality traits by using two trapezoidal fuzzy sets: low $(L)$ and high $(H)$. Finally, 32 combinations of personality were constructed as the rules to the P\&E engine. From these combinations, we can analyze the characteristics for different story character roles and behavior types [38]. The output variables of the character type are represented by five Gaussian membership functions when it represents antagonist, hinder, neutral, helper, or protagonist (Fig. 7). The behavior types are devised by four triangular fuzzy sets: very cold, cold, warm, and very warm. Associated with the fuzzy control law is a collection of linguistic values. The controller output varies between 0 and 1.

A fuzzy rule-based model uses a set of fuzzy if-then rules to capture the relationship between the model's inputs and output. We use 32 if-then rule statements to formulate conditional statements that comprise the personality FLC module. The following example shows how 32 rules can be described in linguistic forms:

If (Openness is Low) and (Conscientiousness is Low) and (Extraversion is Low) and (Agreeableness is Low) and (Neuroticism is Low), then (CharacterType is Hinder) and (BehaviorType is Cold). 
TABLE 5

The Relationship of Behavior and Kinesphere Zones

\begin{tabular}{|l|l|l|}
\hline & Warm behavior & Cold Behavior \\
\hline Horizontal shape & Spreading & Enclosing \\
\hline Vertical shape & Rising & Descending \\
\hline Sagittal shape & Advancing & Retiring \\
\hline
\end{tabular}

During fuzzy inference, all fuzzy rules in a model are fired and combined to obtain a fuzzy conclusion for each output variable. The implication result is a fuzzy set which is the minimum of membership functions of the input and output. The minimum membership value for the antecedent (input) propagates to the consequent and truncates the membership function for the consequent (output) of each rule. There are several different types of fuzzy rule-based models. The two most popular are the Mamdani and Assilian model [39] and the Takagi-Sugeno model [40]. We choose the Mamdani and Assilian model with the centroid defuzzification as an example.

The implication result obtained from each rule should be aggregated and defuzzified to obtain a single value. We aggregate the rule outputs by applying the maximum t-conorm rule for aggregation method. Each fuzzy conclusion is then defuzzified, resulting in a final output. The center of gravity (centroid) technique is used as a defuzzified method to convert the results to output value.

The results of the first layer can assist with the authoring process. By taking the outcomes of the personality and behavior type as a guideline, an author or a story designer can evaluate the results and decide to fine-tune the parameters for enhancing performance. The results of the first layer can also be used to develop a subsystem (e.g., a character's appearance module).

\subsubsection{Emotion FLC Module}

After receiving the outcomes of the character and behavior types produced from the personality FLC system, these two factors couple with the emotion outcome from story input module to become input variables of the emotion FLC system. At present, there are six basic emotions that the FLC system constructs with happy, surprise, angry, sad, angry, disgust, and fear. Similarly, we can later devise the combination of mixed emotions or moods (e.g., happiness and surprise, anger and fear, or anger and disgust, etc.) as fuzzy rules and appended to the system. We take "happiness" as an instance. The other five emotion FLC systems are constructed in this similar structure. Input variables of the happy emotion FLC module are devised as the three triangular membership functions when it represents neutral, low, or high.

The output variables of happy emotion FLC module are these three kinesphere zones of human body: horizontal $(H)$, vertical $(V)$, and sagittal $(S)$. The output variables are depicted by five Gaussian fuzzy sets. The horizontal outputs are Very Enclosing (VEn), Enclosing (En), Neutral (N), Spreading (Sp), or Very Spreading (VSp). The vertical outputs are Very Descending (VDe), Descending (De), Neutral (N), Rising (Ri), or Very Rising (VRi). In addition, the output variables of sagittal are Very Retiring (VRe), Retiring (Re),

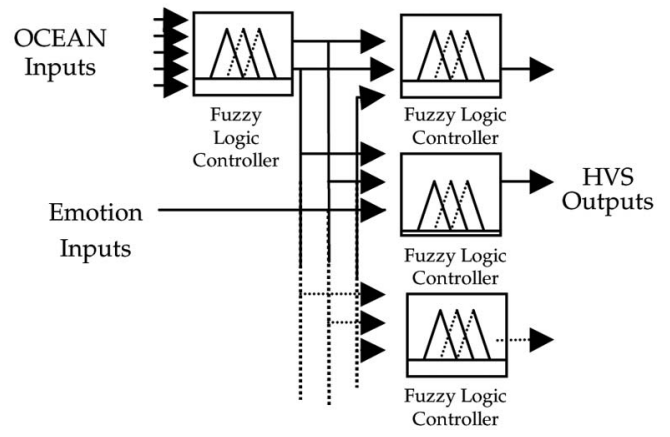

Fig. 8. Basic configuration of the hierarchical fuzzy logical control.

Neutral (N), Advancing (Ad), or Very Advancing (VAd). The controller outputs vary between -1 and 1.0 means Neutral.

For computational purposes, we simplify the fuzzy rules based on the theory of the story character, personality, and emotion, and map them to the human behavior described in Section 4. For instance, we exclude that an antagonist has very warm or warm behaviors based on the description of 32 trait combinations. As a result, there are 48 fuzzy rules devised for each emotion FLC. The rules of the basic six emotion FLC modules are implemented similarly to the personality FLC module. The final form of the happy emotion rules is expressed in the following example:

If (CharacterType is Protagonist) and (BehaviorType is VWarm) and (Happy is H), then (Horizontal is VSp) and (Vertical is Ri) and (Sagittal is VRe).

Rules are based on the depiction of warm or cold behaviors which determine the intensity or duration of a certain emotion. For instance, a person is prone to be a protagonist with very warm behaviors. If her/his emotion is very happy, then her/his actions will be dramatically spreading in horizontal, rising in vertical, and retiring in sagittal shapes. Moreover, moods and the mixed emotions can also be devised as fuzzy rules and be appended to the system. Table 5 lists these three shaping components of kinesphere zones in relation with these motion parameters.

Fig. 8 shows the abbreviated basic configuration of our P\&E engine. OCEAN inputs are values of personality $(0 \sim 1)$. The outputs are HVS values of the body posture $(-1 \sim 1)$. Fuzzy logic improves the classification and the decision system of personality and emotion for the story characters' behavior. It also improves the interpretability of the results by providing more insight into the classifier structure and decision making systems.

\subsection{Mapping the P\&E Engine to Animation and Graphics Engine}

Human motions and our animation engine are implemented by using Maya as the visualization environment. The hierarchical skeleton of our character is constructed by 32 joints (Fig. 9). We use our skeleton to drive different character models and render them in Maya.

After receiving the output postural value from Matlab, our P\&E plug-in in Maya updates the values. The Maya Embedded Language (MEL) is a powerful high-level command and scripting language that offers direct control over Maya's features, processes, and workflows. It plays 


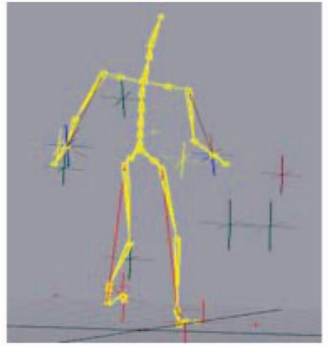

Fig. 9. Hierarchical joint skeleton.

two roles: One is communicative for supplying the motion data to Dependency Graph (DG) Node and manipulating the shape node that stores the model's geometry. The other is for loading, executing, and unloading the P\&E plug-in interfaces and procedures to carry out modeling, animation, dynamics, and rending tasks.

Based on the four main body areas of human motion, the physical parameters corresponding to the body kinesphere zones of shape are constrained based on the physical characteristics of sex and space, timing, velocity, position, height, weight, and portion of the body. These are the physical parameters emphasized in 12 principles of typical animation techniques for believable characters [41]. For example, $\$ \operatorname{Leg} Y=-\operatorname{Sin}\left(\text { Time }^{*} \$ \text { Frequency }\right)^{*} \$$ Amplitude + $\$ O f f$ set shows how we deal with the speed, amplitude and height of one of a character's legs. In Table 6, we compare the relationship between emotions and some physical parameters. When a character is happy, the velocity of his actions will be faster and the space is more flexible. Conversely, when a character is sad, the movements will be slower and restrained.

A characters' limbs are controlled by the Inverse Kinematics (IK) solver. Maya's built-in IK solver is used to control the posture and motions as it is faster and more consistent. This saves much time from a lot of low level implementations. We then collect a set of data of each motion interpolation from an animated model listed in Table 7 . Therefore, we are able to control the idle posture of a character by fitting curves to data. By fitting curves to data, we create an equation $y=$ $a x^{2}+b x+c$ for each motion, where $x$ is one output variable of Horizontal, Vertical, and Sagittal HVS, and $y$ is one of the motion parameters. For instance, $\$$ LegSpread $=0.194^{*}(\$ H)^{2}$ $\left.-0.5^{*}\right)+0.23$. $\$ H$ means "Horizontal" varying between -1 (Enclosing), 0 (Neutral), and 1 (Spreading).

The Animation and Graphics engine receives the possible postural values of horizontal, vertical, and sagittal orientation. The movement of the character remains in a consistent postural threshold as well as her/his possible habitual gestures are limited to display the specific

TABLE 6

Emotions and Physical Parameters

\begin{tabular}{|l|l|l|}
\hline & Positive emotions & Negative emotions \\
\hline Weight & Light & Strong \\
\hline Velocity & Presto-quick & Lento-slow \\
\hline Space & Flexible & Restrained \\
\hline Flow & Free rhythmical & Bound \\
\hline
\end{tabular}

TABLE 7

Motion Parameters Related to Three Kinesphere Zones and Timing

\begin{tabular}{|l|l|}
\hline & Motion Parameters \\
\hline Horizontal & $\begin{array}{l}\text { Head_side, Arm_spread, Spine_side, Leg_spread, } \\
\text { Hip_swing, Spine_side, Leg_spread, Leg_offset, } \\
\text { Knee_offset, Feet_spread }\end{array}$ \\
\hline Vertical & Head_node, Shoulder_shrug, Hand_height \\
\hline Sagittal & Spine_bend, Shoulder_retract \\
\hline Timing & $\begin{array}{l}\text { Hand_frequency,Hand_amplitude, Leg_frequency, } \\
\text { Leg_amplitude, Body_noise }\end{array}$ \\
\hline
\end{tabular}

personality of the character. We physically constrain the movements of an animated model and collect a set of data of each motion interpolation. By passing parameters to a nonlinear animation editor (Trax editor) in Maya, the Trax editor can be used to position, scale, cycle, and mix animation sequences, and to be able to change the sequence of gesture or gesture clips (Fig. 10), for instance, arms crossed, arms akimbo, and scratching the head. The nonlinear animation is a way to layer, blend, and mix character animation sequences including motion capture and path animation nonlinearly, independent of time. It allows a nodular approach to the animation, where different clips are created then mixed down. Once created, a clip is like a time-independent unit of animation that the user can edit. To evaluate our system, we have two examples as our testbeds.

\subsubsection{Example 1: Walkcycle Control Based on Personality and Emotion}

We create a walk cycle motion by a procedure describing the frequency of paces and the motion parameters previously mentioned. We hypothetically modulate the crisp values $1,0.1,1,1$, and 0 (HLHHL) correspondingly to OCEAN parameters in the P\&E controller. In this case, we rate Openness as 1, which will be given to our graphical definition of Openness, corresponding to the "high" membership function. Similarly, Conscientiousness is rated as "low" with value 0.1 . This person has the characteristics of excitement-seeking, reckless, cheerful, boisterous, versatile, changeable, bold, etc. The results of personality FLC are defuzzified to obtain crisp values of 0.29 and 0.64 for the

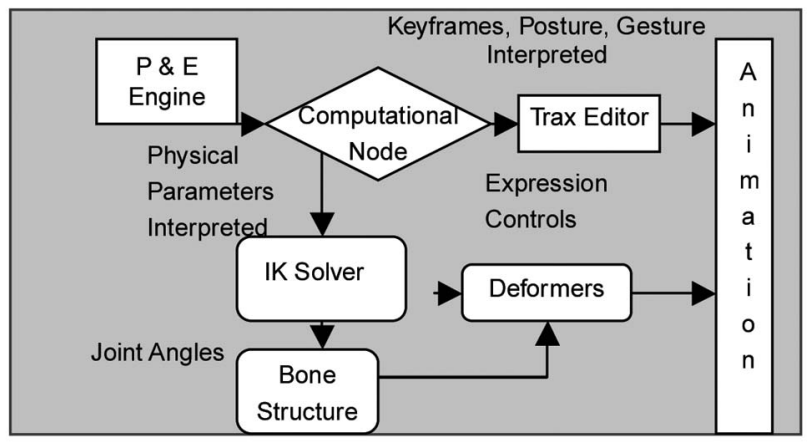

Fig. 10. Animation and graphics engine architecture. 


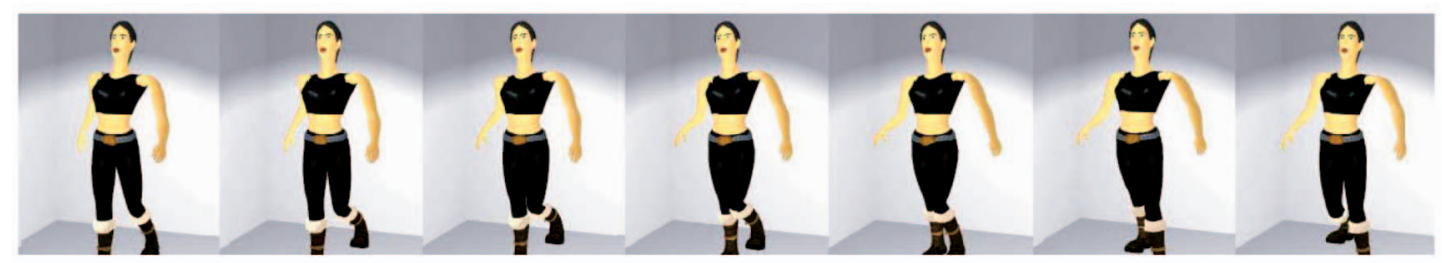

(a)

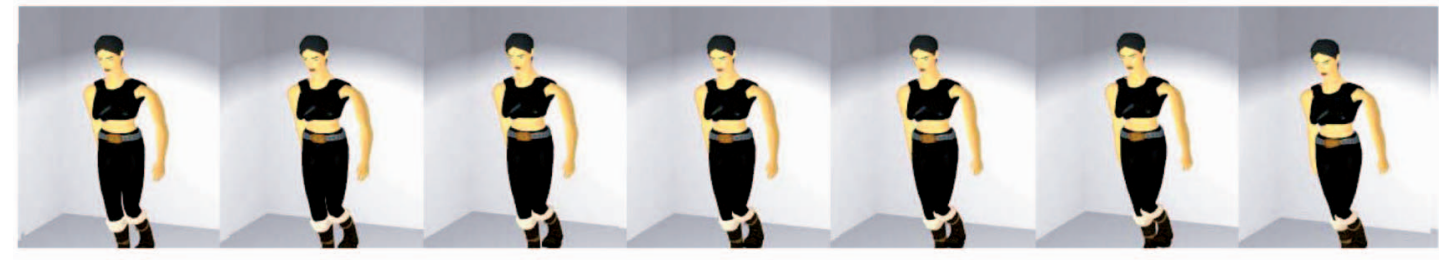

(b)

Fig. 11. Example 1: The comparison of different personality and emotion. (a) Personality (HLHHL): Excitement-seeking, foolhardy; emotion: happy; behavior type: very warm; character type: hinder. (b) Personality (HHLLH): Dominant, juvenile department; emotion: sad; behavior type: very cold; character type: antagonist.

character type "hinder" and the behavior type inclining to "very warm." If the user also inputs crisp value 1 (highly) for emotion type "happy," the result of emotion FLC shows the character's body posture such as retiring backward, more body swinging, and relaxed. The frequency of pace is agile. The values of HVS are 0.61, 0.36, and -0.36, respectively.

The Animation and Graphics engine updates the values of the kinesphere zone, and the character then changes to an idle posture which suits her habitual movement (Fig. 11a). In comparison with the inputs $0.9,0.6,0.1,0.1$, and 0.86 (HHLLH) for OCEAN, we get the values 0.69 and 0.3 for the story character type "protagonist" and the behavior type "very cold." This type of person is aggressive, adventurous, ill-tempered, dominant, explosive, cold-blood, and juvenile delinquent. The emotional state remains as "happy," HVS values of the result are $0.36,0.67$, and -0.37 , which manifests the character only slightly spreading, retiring, and less body swinging. If the user inputs crisp value 1 (highly) for emotion type "sad," HVS values of the result are $-0.62,-0.62$, and 0.62 (Fig. 11b). The result of emotion FLC manifests that the character is dropping her shoulder, hunching her back, lowering her body weight, and being motionless. Some preliminary informal feedbacks have been obtained from colleagues which indicate that the differential effect of personality types is believable.

\subsubsection{Example 2: Descriptive Story Input Based on Body Language}

To illustrate how our story approach responds to the challenges in Section 2, we devise six basic different dialogue scenarios for testing our prototype in our story interface. Basic dialogues consist of three segments: standing alone, meeting the man, and following/not-following the man (Table 8). We derive and differentiate the varieties of dialogues, descriptions, and action data in the conception of the storyboard. From this scenario, we are able to develop more than 100 various combinations of body postures or gestures for selection. For example, in scene 3 , action descriptions supply the perceptual communication needs which express she is careful, nervous, and defensive. If a dialogue copes with different postures or gestures, the meaning of the body language will be different. A comparison in Table 9 shows that an author can choose either the second or third row. The same dialogue coupling with different actions can produce different meanings of a body language. The second row of Table 9 shows that she is nervous, anxious, and ill-tempered. The third row of Table 9 shows she is bashful and embrassed.

From the results of accumulated adjectives of body languages, we evaluate the maximum frequency of these lexicons. We take the story in Table 8 as an example. The selections of story input module become the input value to the P\&E Engine. The result from the P\&E engine shows Ally

TABLE 8

One of the Proposed Scenarios

\begin{tabular}{|c|l|l|c|}
\hline Scene & $\begin{array}{l}\text { Story Scripts } \\
\text { By Script Supervisor }\end{array}$ & $\begin{array}{l}\text { Actions Directed } \\
\text { By Director }\end{array}$ & $\begin{array}{l}\text { Time } \\
\text { Dura- } \\
\text { tion }\end{array}$ \\
\hline 1 & $\begin{array}{l}\text { Ally is carrying her } \\
\text { suitcase. She is lost in } \\
\text { a bus terminal of an } \\
\text { airport. }\end{array}$ & $\begin{array}{l}\text { She stands stiff and } \\
\text { folds her arm in the } \\
\text { front. She nervously } \\
\text { looks around. }\end{array}$ & $1^{\prime} 30^{\prime \prime}$ \\
\hline 2 & $\begin{array}{l}\text { A passing man offers } \\
\text { her help. } \\
\text { Can I help you? }\end{array}$ & $\begin{array}{l}\text { He is in an open pos- } \\
\text { ture. }\end{array}$ & $1^{\prime}$ \\
\hline 3 & $\begin{array}{l}\text { < Ally > I am not sure, } \\
\text { I think," I am lost." } \\
\text { tral station. }\end{array}$ & $\begin{array}{l}\text { She erects her back, } \\
\text { stares at the man and } \\
\text { embarrassedly chuck- } \\
\text { les. She clenches her } \\
\text { arms in lower position } \\
\text { and leans backward. }\end{array}$ & 1 ' \\
\hline 4 & $\begin{array}{l}\text { <Man> You can follow } \\
\text { me to the corner. } \\
\text { There is a map. I can } \\
\text { help you carry this } \\
\text { suitcase. }\end{array}$ & $\begin{array}{l}\text { He points to the map } \\
\text { direction. } \\
\text { He reaches for her } \\
\text { suitcase. }\end{array}$ & 40" \\
\hline 5 & $\begin{array}{l}\text { <Ally > "No, I am } \\
\text { appreciated. It's very } \\
\text { nice of you to ask. I } \\
\text { will carry it myself." } \\
\text { Please, after you. }\end{array}$ & $\begin{array}{l}\text { She is in a close pos- } \\
\text { ture and waves at the } \\
\text { man. She carries her } \\
\text { suitcase by herself. } \\
\text { She politely follows the } \\
\text { man slowly. }\end{array}$ & $1^{\prime}$ \\
\hline
\end{tabular}


TABLE 9

The Comparison of Scene 3

\begin{tabular}{|c|l|l|}
\hline Scene & Story Scripts & Actions \\
\hline 3 & $\begin{array}{l}<\text { Ally }>\text { No, I am } \\
\text { fine. }\end{array}$ & $\begin{array}{l}\text { She has no smile and nibbles her fin- } \\
\text { gernails. She than has her arms } \\
\text { akimbo. She leans backward and yells. }\end{array}$ \\
\hline 3 & $\begin{array}{l}<\text { Ally }>\text { No, I am } \\
\text { fine. }\end{array}$ & $\begin{array}{l}\text { She stands at ease, scratches her } \\
\text { head, and says with a soft chuckle. }\end{array}$ \\
\hline
\end{tabular}

has a personality high in OCEA and low in N (HHHHL), shown in Fig. 12a. Her character type is prone to be a protagonist (0.9338) and her behavior type is very warm (0.7498). The emotion of the first scene is also updated in the P\&E engine. In scene 1, her emotional state is slightly angry. In scenes 3 and 5, her emotion becomes slightly happy.

From the results of the P\&E engine, the Animation and Graphics engine received possible postural values of horizontal, vertical, and sagittal orientations. The movement of the character will remain in a consistent postural threshold as well as her/his possible habitual gestures are limited in certain types to display the specific personality of the character. Therefore, her habitual postures are prone to be spreading, rising, and advancing in HVS zones. In scene 1, HVS values are -0.2139, -0.4998, and 0.2139, respectively, because she is slightly angry. In Scenes 3 and 5 , HVS values change to $0.69,0.69$, and -0.3 because she is slightly happy. The animation engine updates HVS values and influences the effects of character's general or habitual idle posture and gesture selections that are predefined motion database. To show the comparison of two different story scenarios, we change scene 3 to the second row of Table 9 and scene 5 to "<Ally>: What are you up to? Leave me alone. <Action>: She stares at the man from head to toes. She assuredly walks away by herself." The outcome for this personality is HHHLH, Ally's emotional states of scenes 3 and 5 change to neutral and slightly angry. Fig. 12b displays some types of gesture and posture corresponding to the unfolding story.
Along with the different story combinations, a character's postural motions always refer to the change of her personality and emotion states. If the result fell short of story designer's exceptions, it is possible to refine the input value of the $P \& E$ engine for better performance.

\section{Conclusion And Future Work}

In this paper, we have compared the relationship between personality, emotion, and nonverbal communication of the story characters as well as devised a method with insight into characters' cognitive states with psychological theories. We have constructed a hierarchical MIMO fuzzy rule-based system for the P\&E engine to generate body expressions from a story character's personality and emotion states.

With psychology-based fuzzy rules, postures are generated to facilitate a story character control on their movements including stance, walking, running, etc. In our story scripts study, the implicative results of body language contain the predictability of personality type. This finding can be utilized in the narrative interaction between story agents and provide a set of nonrepetitive postures and actions based on their personalities.

The goal of the research is to allow narrative characters to embody intelligent-like ability, flexibility, and styling performance. Our P\&E engine may also be used in the animation production, psychological education analysis, or interactive entertainment industry. The system is scalable by adding the combination of emotions and provides unpredictable possibilities. For instance, moods and mixed emotions (e.g., happiness and surprise, anger and fear, or anger and disgust, etc.) can be devised as fuzzy rules and be appended to the system. In our present work, the physical status, cultural factors, and facial expressions of a story character are not within the scope of this research. The system is yet limited by the variety of the motion and gesture database and text inputs for dialogues. The

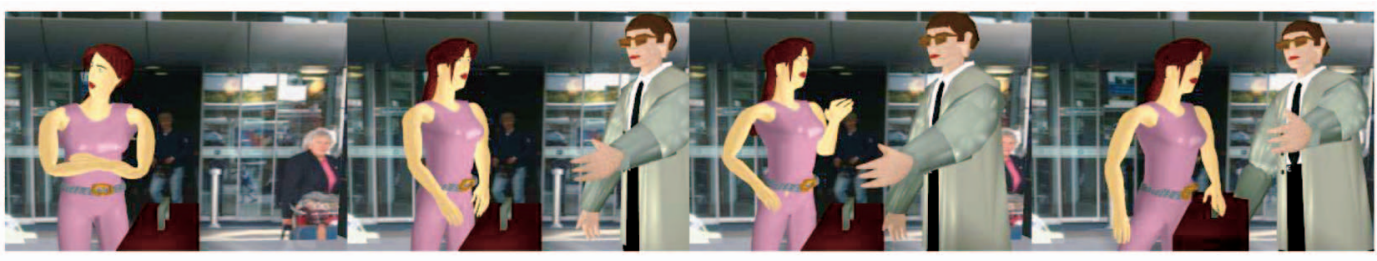

(a)

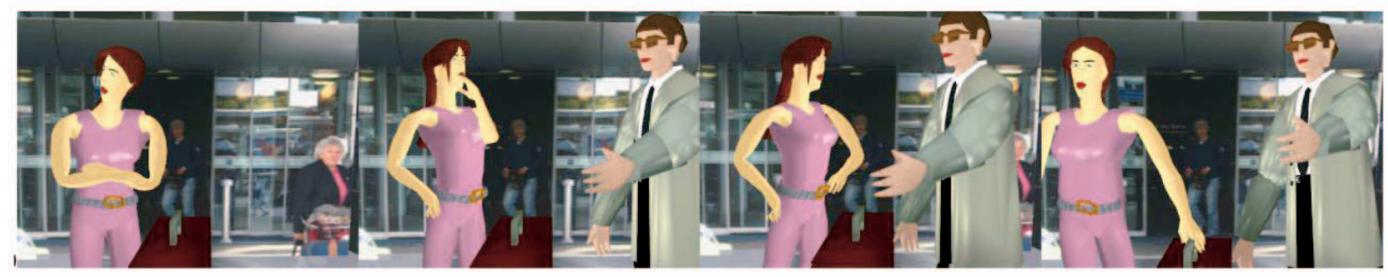

(b)

Fig. 12. Example 2: The comparison of two different scenarios. (a) She nervously looks around. She clenches her arms in lower position. She then follows the man. (b) She nervously looks around. She nibbles her fingers. She has her arms akimbo, leans backward, and yells. She then walks away. 
interaction between two characters is still restricted because the male character's dialogue and actions remain the same.

In our ongoing research, we will investigate the following aspects of the P\&E engine: How does an agent perceive the body language of the other interlocutor and respond to him/ her based on his/her own personality? In addition, a good story character has contrast in shapes such as big and small, triangle to round, thin to fat, or straight to curly. All proportions of the body should not be equal, i.e., a small head plus a big barrel-like chest, short legs plus long arms, etc. A good character will hold an audience's interest and empathy. What elements does the appearance consist of? We will construct computational rules for character appearances by adding a cartoon-style character controlling. We will continue to investigate the mechanisms of narratives in the interaction design. The problem of giving the audience control of a story is that they will often, quite reasonably, act to reduce tension and avoid conflict. However, tension and conflict are the spirit of great stories [1]. Therefore, how to let a user interact with a character and abide by the essence of drama is the next challenge. Moreover, further formal evaluations will have to be carried out.

\section{REFERENCES}

[1] A.S. Glassner, Interactive Storytelling: Techniques for 21st Century Fiction. Coyote Wind, LLC, 2004.

[2] L. Chittaro and M. Serra, "Behavioral Programming of Autonomous Characters Based on Probabilistic Automata and Personality," J. Computer Animation and Virtual Worlds, vol. 15, nos. 3-4, pp. 319-326, July 2004.

[3] D. Rousseau, "Personality in Computer Characters," Proc. AAAI96 Workshop Entertainment and AI/A-Life, pp. 38-43, Aug. 1996.

[4] B. De Raad, The Big Five Personality Factors, The Psycholexical Approach to Personality. Hogrefe \& Huber, 2000.

[5] K. Amaya, A. Bruderlin, and T. Calvert, "Emotion from Motion," Proc. Graphics Interface Conf., 1996.

[6] M. Unuma, K. Anjyo, and R. Takeuchi, "Fourier Principle of Emotion-Based Human Figure Animation," Proc. SIGGRAPH, 1995.

[7] C.F. Rose, B. Guenter, B. Bodenheimer, and M. Cohen, "Verbs and Adverbs: Multidimensional Motion Interpolation Using Radial Basis Functions," IEEE Computer Graphics and Applications, vol. 18, no. 5, pp. 32-40, Sept./Oct. 1998.

[8] I. Wilson, "The Artificial Emotion Engine, Driving Emotional Behavior," Proc. AAAI Spring Symp., 1999.

[9] J.D. Velasquez, "Modelling Emotions and Other Motivatons in Synthetic Agents," Proc. AAAI-97, 1997.

[10] K. Perlin, "Real Time Responsive Animation with Personality," IEEE Trans. Visualization and Computer Graphics, vol. 1, pp. 5-15, 1995.

[11] K. Perlin and A. Goldberg, "Improv: A System for Scripting Interactive Actors in Virtual Worlds," Computer Graphics, vol. 29, 1996.

[12] E.T. Hall, The Silent Language. Doubleday, 1959.

[13] M. Argyle, Bodily Communication. Methuen \& Co., 1988.

[14] D. Chi, M. Costa, L. Zhao, and N. Badler, "The EMOTE Model for Effort and Shape," Proc. SIGGGRAPH '00, ACM Computer Graphics Ann. Conf., pp. 173-182, July 2000.

[15] A. Egges, T. Molet, and N. Magnenat-Thalmann, "Personalized Real-Time Idle Motion Synthesis," Proc. 12th Pacific Graphics Conf., pp. 121-130, Oct. 2004.

[16] J. Cassell, H.H. Vilhjalmsson, and T. Bickmore, "BEAT: The Behavior Expression Animation Toolkit," Proc. ACM SIGGRAPH '01, pp. 477-486. Aug. 2001.

[17] E. Andre, T. Rist, and J. Muller, "Employing AI Methods to Control the Behavior of Animated Interface Agents," Applied Artificial Intelligence, vol. 13, pp. 415-448, 1999.

[18] M. Stone, D. DeCarlo, I. Oh, C. Rodriguez, A. Stere, A. Lees, and C. Bregler, "Speaking with Hands: Creating Animated Conversational Characters from Recordings of Human Performance," Proc. SIGGRAPH, 2004.
[19] A.B. Loyall and J. Bates, "Personality-Rich Believable Agents that Use Language," Proc. First Int'l Conf. Autonomous Agents, 1997.

[20] V. Propp, "Morphology of the Folktale," Int'l J. Am. Linguistics, vol. 24, 1968.

[21] R. McKee, Story-Substance, Structure, Style, and the Principle of Screenwriting, first ed. Harper-Collins, 1997.

[22] L.N. Edelstein, The Writer's Guide to Character Traits: Includes Profiles of Human Behaviors and Personality Types. Writer's Digest Books, 1999.

[23] N. Frijda, A. Orthony, J. Sonnemans, and G.L. Clore, "The Complexity of Intensity: Issues Concerning the Structure of Emotion Intensity," Emotion: Rev. of Personality and Social Psychology, vol. 13, pp. 60-89, 1992.

[24] R.R. McCrae and O.P. John, "An Introduction to the Five Factor Model and Its Applications. Special Issues: The Five-Factor Model: Issues and Applications," Personality, vol. 60, pp. 175-215, 1992.

[25] S. Kshirsagar and N. Magnenat-Thalmann, "A Multilayer Pesonality Model," Proc. Second Int'l Symp. Smart Graphics, 2002.

[26] A. Egges, S. Kshirsagar, and N. Magnenat Thalmann, "A Model for Personality and Emotion Simulation," Proc. Knowledge-Based Intelligent Information \& Eng. Systems (KES '03), pp. 453-461, 2003.

[27] M.C. Embree, "Reflections on Personality Diversity," http:// www.uwmc.uwc.edu/psychology/personality_diversity.htm, 2004.

[28] N. Nicholson, M. Fenton-O'Creevy, E. Soane, and P. Willman, "Risk Propensity and Personality," London Business School, Univ. of London, http://facultyresearch.london.edu/docs/risk.pdf, 2002.

[29] D. McNeill, Hand \& Mind-What Gestures Reveal about Thought. Univ. of Chicago Press, 1992.

[30] P. Ekman, "An Argument for Basic Emotions," Basic Emotions, N. Stein and K. Oatley, eds. Lawrence Erlbaum, pp. 169-200, 1992.

[31] P.E. Bull, Posture and Gesture, vol. 16. Pergamon Press, 1987.

[32] M.L. Knapp, Essentials of Nonverbal Communication. Holt, Rinehart, and Winston, 1980.

[33] W. Lamb and E. Watson, Body Code-The Meaning Movement. Princeton Book Company, 1979.

[34] J. Lasseter, "Tricks to Animating Characters with a Computer," Proc. SIGGRAPH '94 course note "Animation Tricks," 1994.

[35] R.C. Berkan and S.L. Trubatch, Fuzzy Systems Design PrinciplesBuilding Fuzzy If-Then Rule Base. IEEE Press, 1997.

[36] M.S. El-Nasr, J. Yen, and T.R. Ioerger, "FLAME-Fuzzy Logic Adaptive Model of Emotions," Autonomous Agents and Multi-Agent Systems, vol. 3, pp. 219-257, 2000.

[37] T.D. Bui, D. Heylen, M. Poel, and A. Nijholt, "Generating of Facial Expressions from Emotion Using a Fuzzy Rule Based System," Proc. AI '01-14th Australian Joint Conf. Artificial Intelligence, 2001.

[38] W. Su, B. Pham, and A. Wardhani, "High-Level Control Posture of Story Characters Based on Personality and Emotion," Proc. IE '05, The Second Australasian Interactive Entertainment Conf., pp. 179-186, 2005.

[39] E.H. Mamdani and S. Assilian, "An Experiment in Linguistic Synthesis with a Fuzzy Logic Controller," Int'l J. Machine Studies, vol. 7 , no. 1 , pp. $1-13,1975$.

[40] T. Takagi and M. Sugeno, "Fuzzy Identification of Systems and Its Applications to Modeling and Control," IEEE Trans. Systems, Man, and Cybernetics, vol. 15, pp. 116-132, 1985.

[41] F. Thomas and O. Johnson, Disney Animation: The Illusion of Life. Abbeville Press, 1984. 


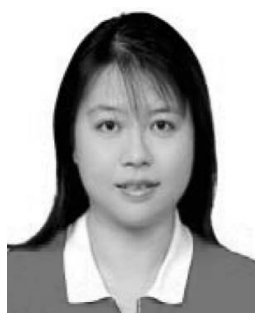

Wen-Poh Su received the MS degree in information techology in 1999, the MFA degree in film, video, and 3D animation in 1998, and the Advance Graduate Interactive Media Design certificate in 1997 from the Rochester Institute of Technology. She is a $\mathrm{PhD}$ candidate in information technology at the Queensland University of Technology, Australia. In 2002, she was a lecturer at Shih Chien University and Hsuan Chuang University, Taiwan. She also worked as an art director for news broadcasting in Chinese television systems for eight years. Her research interests include 3D computer animation, believable agent, human behavior simulation, ambient intelligence, and narrative intelligence. She is a student member of the IEEE.

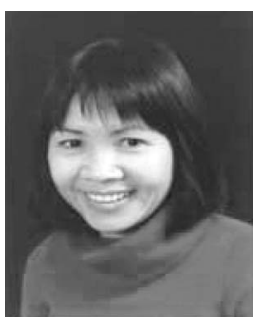

Binh Pham has been the Director of Research on the Faculty of Information Technology at the Queensland University of Technology since 2000. Prior to this, she held the IBM Foundation Chair in Information Technology at the University of Ballarat from 1995-1999 and was an associate professor in the School of Computing and IT at Griffith University from 1993-1995. Her research interests cover computer graphics, image processing, multimedia, visualization, spatial and temporal data mining, intelligent systems, and their application to real-world problems. She is a member of the IEEE.

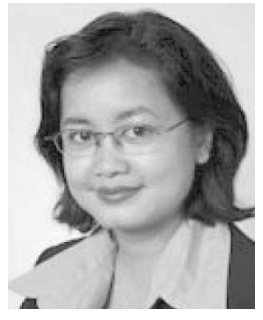

Aster Wardhani received the BEng degree in electrical engineering from Wollongong University, Australia, in 1996, and the PhD degree in information technology from Griffith University, Australia, in 2001. Since 2001, she has been a lecturer at the School of Software Engineering and Data Communications, Queensland University of Technology, Brisbane, Australia. Her research interests include visual information retrieval, image segmentation, computer graphics and games, and medical image processing. She is a member of the IEEE.

$\triangleright$ For more information on this or any other computing topic, please visit our Digital Library at www.computer.org/publications/dlib. 